\title{
NORUEGA COMO ESPACIO PERIFÉRICO EN LA DEPURACIÓN DEL MODERNISMO HISPÁNICO. EL CASO DE EFRÉN REBOLLEDO Y SU LIBRO SAGA DE SIGRIDA LA BLONDA (1922)
}

\author{
Emilio Quintana Pareja ${ }^{1}$ \\ Instituto Cervantes de Estocolmo
}

A V. R. T., para quien escribí estas páginas.

\section{Resumen}

En este ensayo queremos iluminar en lo posible la etapa noruega de la vida y obra del escritor y poeta mexicano Efrén Rebolledo (1877-1929). Nos centramos en especial en su "novella" autobiográfica Saga de Sigrida la Blonda (Kristiania, Det Mallingske Bogtrykkeri, 1922). Noruega se revela para el escritor mexicano como un espacio periférico en relación con un centro parisino (París como Babel del modernismo sensualista), en el que es posible la redención regeneradora mediante el descubrimiento del revés inmaculado de la estética decadente, estética que Rebolledo no deja nunca de cultivar. Conectamos este cruce estético con el del poeta español Antonio de Zayas (1871-1945), modernista "casticista", según denominación asentada, Embajador de España en Estocolmo durante dos períodos entre 1902 y 1918. La significación de lo nórdico en la obra de ambos poetas diplomáticos (que incluye el ensayo "Piscología y costumbres del pueblo escandinavo", que Zayas publica en 1907), nos sirve para llamar la atención sobre aspectos fundamentales de la relación entre el modernismo hispano y la necesidad de una regeneración nacional tras la debacle de 1898.

\footnotetext{
${ }^{1}$ Emilio Quintana Pareja (Granada, 1964) es Doctor en Filología Hispánica. Ha sido profesor titular de la Universidad de Granada hasta 2003. Ha trabajado igualmente en las Universidades de Lund (Suecia) y Pavía (Italia). Profesor de plantilla en diversos centros del Instituto Cervantes (Italia, Holanda y Suecia) es actualmente coordinador académico del Instituto Cervantes de Estocolmo. Uno de sus principales campos de estudio tiene relación con los estudios culturales hispano-nórdicos, habiendo publicado varios estudios, así como traducciones, entre las que destaca la de Liquidación de ideales (Granada, El Genio Maligno, 2014), poemario de vanguardia del poeta sueco-finés Henry Parland (1908-1930). Algunas de sus numerosas publicaciones pueden consultarse en línea, en https://cervantes.academia.edu/EmilioQuintana
}

equintan@gmail.com 


\section{Nordic Journal of Modern Language Methodology}

Palabras clave: Nordismo; Rebolledo; Decadentismo; Zayas; Modernismo; Noruega; Escandinavia; Fin de siglo; Art nouveau.

\section{Introducción}

El mundo de la cultura hispana conmemoró en 2017 el 140 aniversario del natalicio del poeta modernista mexicano Efrén Rebolledo (Actopan, 1877-Madrid, 1929; su nombre original era Santiago Procopio). En este trabajo queremos iluminar en lo posible la etapa noruega de la vida y obra de un autor que ha sido recordado recientemente por el chileno Roberto Bolaño en su novela de culto Los detectives salvajes (Bolaño, 1998), en la que cita una versión erótica del poema "Vampiro". Nos centramos en especial en la "novella" autobiográfica de Rebolledo que lleva por título Saga de Sigrida la Blonda (Kristiania, Det Mallingske Bogtrykkeri, 1922), uno de los libros que publicó durante su estancia como diplomático en Oslo (1919-1922).

Efrén Rebolledo (algunos de cuyos descendientes siguen el oficio literario de su antepasado en la Noruega actual, caso de su nieto (poeta) Torgeir Rebolledo Pedersen (Nes, Romerike, 3-08-1949), que se ha referido a su abuelo en algunas ocasiones (Økland, 2015), es un ejemplo sublime de fidelidad al canon modernista decadente, que encuentra en Noruega las condiciones para un giro hacia un parnasianismo culturalista igualmente rico, pero mucho más depurado de sensualismo. Los libros que se editaron en Cristiania en 1922 no han recibido hasta la fecha la atención que merecen.

Tengo constancia de que Rebolledo publicó tres libros en 1922 en la imprenta fundada por el Sr. Peter T. Malling (Det Mallingske Bogtrykkeri), y en tiradas de 1000 ejemplares:

- Joyelero. Kristiania [Oslo], Det Mallingske Bogtrykkeri, 1922 [poesías completas]; reimpreso con cambios en Madrid, en la Imprenta de Galo Sáez, 1929 [antología]. La edición noruega puede consultarse en línea: http://bdhrd.bne.es/viewer.vm?id=0000043897\&page $=1$

- Salamandra. Kristiania [Oslo], Det Mallingske Bogtrykkeri, 1922. Esta es una novela corta que vio la luz en la Ciudad de México en 1919 (Talleres Gráficos del Gobierno, 1919; 500 ejemplares). Esta segunda edición noruega (datada 


\section{Nordic Journal of Modern Language Methodology}

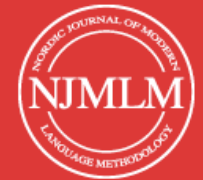

2019, 7 (2), 154-173 Peer reviewed Temanummer: Spansk i Norge og det norske i den spansktalende verden.

en México en "junio de 1922"; 1000 ejemplares) presenta cambios significativos respecto a la primitiva edición mexicana, por ejemplo, párrafos completamente rehechos, "con una reescritura del texto a fin de reforzar los aspectos eróticos de la protagonista, su sensualidad y su ambiente" (Rebolledo, 2009). Los ejemplares de la edición noruega son difíciles de encontrar, pero hay una publicación moderna (Rebolledo, 2009) basada en el ejemplar conservado en la biblioteca del Instituto de Investigaciones Doctor José María Luis Mora. Barrera Barrios (2010) le ha dedicado una memoria de licenciatura, pero todavía hay espacio para un estudio más completo.

- Saga de Sigrida la Blonda, Kristiania [Oslo], Det Mallingske Bogtrykkeri, 1922.

La poética de Rebolledo estuvo marcada por sus frecuentes estancias en el extranjero. Su ingreso en el cuerpo diplomático en 1901 le permitió representar a México en varias y lejanas naciones: Cuba, Chile, Guatemala, Francia, Holanda, China, Japón —donde residió casi una década, en una estancia muy importante para su obra, y para la evolución de la literatura hispánica en general (Bogarín Quintana, 2010). A los ojos de sus contemporáneos, Rebolledo era un diplomático "de medio pelo", de origen indio (raza otomí), bizco y con gafas, es decir, no era considerado un aristócrata de sangre, sino un aristócrata del Arte. Este aspecto de su fisonomía ha sido destacado con relativa frecuencia (Escamilla Frías, 2007):

El poeta actopense Ramsés Salanueva sostiene que la fealdad de Rebolledo, la pobreza perenne y una más bien mediocre carrera diplomática, fueron labrando en Rebolledo el cuadro psicológico de un esquizoide (alguien tanático, de sentimientos profundos). "Lo consume su desesperación sexual. Pero se declara amante de la belleza".

Rebolledo se incorpora como encargado de negocios (primer secretario, un puesto menor) en agosto de 1919 a la Legación de México en Cristiania (la actual Oslo, Noruega), unos meses después del fin de la Gran Guerra. Llega desde Japón, donde ha pasado una década fundamental en su vida y para su obra. Y se queda 


\section{Nordic Journal of Modern Language Methodology}

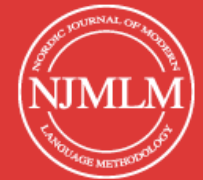

2019, 7 (2), 154-173 Peer reviewed Temanummer: Spansk i Norge og det norske i den spansktalende verden.

hasta 1922, es decir, reside en Noruega entre los 42 y los 45 años. Posteriormente se trasladará a Madrid (1923-1929), donde morirá en tristes circunstancias.

La crítica (Estrada Rubio, 2015, XIV-XV) suele considerar cuatro etapas en su trayectoria literaria, en las que están imbricadas la poesía, la prosa, la traducción y el drama, en buena parte condicionadas por sus actividades plenipotenciarias. En este trabajo nos centraremos en la cuarta etapa:

1. 1900-1907. Periodo inicial. Novelas cortas como El enemigo (1900), los poemarios Cuarzos (1902), Más allá de las nubes (1903) e Hilos de corales (1904), los poemas en prosa y los versos de Estela (1907) y la antología poética Joyeles (1907). En esta época Rebolledo fue un asiduo colaborador de la Revista Moderna.

2. 1907-1910. La segunda etapa de su obra gira en torno al japonismo, que le inspira las Rimas japonesas (1907), las crónicas e impresiones de viaje de Nikko (1910) y la novela Hojas de bambú (1910).

3. 1911-1919. El tercer periodo fue el más fecundo e importante de la carrera literaria de Rebolledo, pues escribió la mayoría de los textos que lo llevaron a ocupar un lugar indiscutible en la historia de la literatura mexicana. Publicó en esta época los poemarios eróticos Libro de loco amor y Caro victrix ("Carne victoriosa"; ambos de 1916), los poemas en prosa de El desencanto de Dulcinea (1916, cuya segunda edición salió de imprenta en 1919), la obra de teatro El águila que cae (1916) y la célebre novela corta Salamandra (1919; reimpresión con correcciones en 1922, en Cristiania). También en este lapso tradujo obras de Rudyard Kipling, Oscar Wilde y Maurice Maeterlinck, y dirigió la revista Pegaso (1917) en colaboración con Ramón López Velarde y Enrique González Martínez.

4. 1919-1929. La última fase de la vida literaria de Rebolledo se caracteriza por la "inspiración nórdica", que tiene como máximo exponente la Saga de Sigrida la blonda (Kristiania, 1922). Esta fase es la menos conocida, a pesar de su importancia. Editó también en Noruega sus poesías completas, bajo el título de Joyelero (1922), que pocos días antes de su muerte fueron reimpresas en Madrid. 


\section{Nordic Journal of Modern Language Methodology}

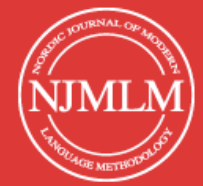

2019, 7 (2), 154-173 Peer reviewed Temanummer: Spansk i Norge og det norske i den spansktalende verden.

Noruega supone un cambio muy importante en la vida personal de Efrén Rebolledo, ya que en 1919 conoce a Thorborg Blomkvist, una hermosa joven rubia, de apenas 19 años, con quien se casa en la primavera de 1921, y con quien tendrá tres hijos: Thor Rebolledo Blomkvist (1921), Efrén Rebolledo Blomkvist (1924-2006), que fue amigo y compañero de trabajo del profesor Juan López Pellicer en la Universidad de Oslo (López Pellicer, 2014), y Gloria Rebolledo Blomkvist.

Su muerte en Madrid en 1929 tuvo algunos aspectos desagradables. Ni hubo dinero para trasladar el cuerpo a México, ni para concederle una pensión a la viuda y los hijos, según pidieron a las autoridades un grupo de literatos mexicanos. Thorborg Blomkvist-Rebolledo murió en condiciones precarias, mientras los restos de su marido fueron a parar a una fosa común (Valencia, 2014):

En 1910, Efrén Rebolledo sufre de una parálisis facial, complicación que diecinueve años más tarde (10 de diciembre de 1929) pone fin a su vida. Fue enterrado en el cementerio de Nuestra Señora de la Almudena. Tres días después, Javier Sánchez Mejorada pidió a Genaro Estrada -ya para entonces Secretario de Relaciones Exteriores- que los restos del poeta fueran trasladados a México. Incluso pidieron una pensión vitalicia para la viuda, la noruega Thorborg Blomkvist, y sus hijos, Thor, Gloria y Efrén. Nada se cumplió: Thorborg murió en la miseria y los restos de Rebolledo nunca fueron traídos a México: el 15 de julio de 1940, al caducar los derechos de suelo, fueron arrojados a la fosa común.

\section{Efrén Rebolledo en Cristiania. Saga de Sigrida la Blonda (1922)}

Estamos ante una novela corta en quince capítulos escrita en Cristiania entre julio y diciembre de 1921, muy poco antes del nacimiento de Thor, su primer hijo. La edición, como queda dicho, fue de mil ejemplares, de los que conozco pocos, uno de ellos el mío. Probablemente el más valioso es el que perteneció al propio autor, que se lo regaló a su hijo Efrén y que ahora está en poder del profesor Juan López Pellicer. Este ejemplar único contiene correcciones del propio autor; por poner un ejemplo, en una de las páginas se corrige "yace postrado" por "está de hinojos" (López Pellicer, 2014 152). La denominación de la historia como saga le da al libro un carácter exótico y reaccionario, ya que lo pone en relación con los viejos escaldas de la nebulosa Islandia (Rebolledo 1922 9). El objetivo declarado del autor (que en realidad supera) es el 


\section{Nordic Journal of Modern Language Methodology}

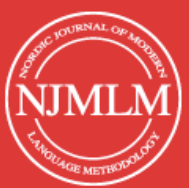

2019, 7 (2), 154-173 Peer reviewed Temanummer: Spansk i Norge og det norske i den spansktalende verden.

siguiente (Rebolledo, 1922 9-10):

Como los viejos escaldas de la nebulosa Islandia inmortalizaron a la apacible Gudruna y a la linda Gelga cubriendo de mágicas runas las hojas de amarillento pergamino, yo quisiera retratar a Sigrida la Blonda en una saga que fuera tan bella como las auroras boreales que a modo de irisados y vaporosos tules entoldan el cielo de Rekjavik (sic).

De hecho, Sigrida aparece relacionada con una porción de mujeres relevantes en la literatura y en la mitología, probablemente tomadas de la iconografía prerrafelita: Isolda, Cordelia, Margarita, Gudruna, Gelga, la dulce Solveig (Peer Gynt) del poema de Ibsen. Sigrida es un ser intempestivo (Rebolledo, 1922 8):

¿Por qué causa, ya consumidos cuatro lustros del Siglo XX, vino al mundo una virgen que debió haber esmaltado la Edad Media, en virtud de haber sido constante como Isolda, callada como Cordelia y pura como Margarita?

La historia se presenta como escrita por el diplomático español Edmundo Serna, trasunto del propio Rebolledo, extranjero que devanó cuatro años inolvidables en la lejana Thulé, ante la añoranza de Sigrida, de la dulce niña de crencha de oro y de ojos azules (Rebolledo, 1922 8). La protagonista que da título a la obra lleva el nombre de Sigrid Lindvist, y pertenece a una familia de la burguesía acomodada de Cristiania, culta y eminentemente práctica, que reside en una villa de Holmenkollen (Rebolledo, 1922 25):

La villa "Mi abrigo", encaramada en una roqueda de Holmenkollen, descuella en medio de los abetos encapuchados de nieve, dejando pasar la luz al través de los cristales de las ventanas.

La niña es hija del ingeniero R. Lindvig, burgués acomodado que fuma puros "sibaríticamente" y lee el Aftenposten. Este padre recuerda a algunos personajes de lbsen, conversa con doctores (el doctor Dahl) sobre temas científicos, y elogia a personajes de referencia como Kielland, Lie, Ibsen, Björson, Hamsun, o Wildenvey. La madre -Fru Lindvig- se dedica a la casa, teje -las mujeres no cosen en el Modernisno, sino que tejen, como damas medievales. Llama la atención que Nick, el hermano de Sigrida, se encuentre en Nueva York, trabajando en un banco, lo que nos conecta con el fenómeno de la emigración nórdica fin de siglo a los Estados 


\section{Nordic Journal of Modern Language Methodology}

Unidos. La vida de Sigrida consiste en su familia, la escuela, los deportes de nieve con amigos, y el cuidado del setter irlandés de la familia. Como chica obediente, a las diez está en la cama.

Con estos antecedentes, lo que nos cuenta Rebolledo es la historia del encuentro, conocimiento, salidas, citas, visitas por la ciudad, lecturas, y el final de los trágicos amores de Edmundo y Sigrida. Aunque el desenlace se ajuste a los parámetros decadentes (Madame Butterfly, el pato salvaje de Ibsen, la Ofelia de Shakespeare a través de los ojos de Everett Millais, la sociología del suicidio en los países nórdicos, el toque d’annunziano de muerte y de belleza...), debemos concluir que, en buena parte, estamos ante un detallado retrato (un homenaje catártico) de la relación entre el autor y la que posteriormente sería su mujer, con escenarios y hechos reales, que evocan una verdadera cartografía de Cristiania en los años 20.

\section{Una cartografía de la Cristiania "art nouveau"}

El libro constituye una especie de baedeker de la ciudad de Cristiania a principios de los años 20. De ahí la referencia contrastiva a Toledo -la ciudad "muerta" de Barrés, en la línea de la Brujas de Rodenbach (Rebolledo 1922 8-9):

¿Por qué motivo nació en la revolucionaria Cristiania, donde triunfan las ideas emancipadoras de Camilla Collett (sic), una criatura que por su docilidad hubo de haber visto la luz en la rancia Toledo?

En esta cartografía literaria encontramos estaciones de tren y conexiones, espacios de esparcimiento, espacios de ocio y belleza, hoteles, eventos sociales, en definitiva, una minuciosa recreación literaria del alma de una ciudad moderna, es decir, refractaria a las ciudades muertas del simbolismo belga. La recreación de esta cartografía sería infinita.

Edmundo ve por primera vez a Sigrida en la estación de Majorstuen (Rebolledo, 1922 12), tomando el tren hacia Holmenkollen con otros compañeros de estudios (su amiga Gilda, cuyos bucles son de un blondo tan oscuro que se antojan de ámbar quemado (Rebolledo, 1922 13), y 3 chicos del instituto: Ingeborg, aspecto felino, flava melena (Rebolledo 1922 13), Rolf, que nunca sabe la lección, y Tura, que sobrepuja a todos en el arte de arrojar pellas de nieve a los profesores sin ser sorprendida en 


\section{Nordic Journal of Modern Language Methodology}

Temanummer: Spansk i Norge og det norske i den spansktalende verden.

flagrante delito (Rebolledo, 1922 14). El noruego se cuela en una frase que hace felices a los colegiales, cuando el profesor de matemáticas les dice:

\section{-Du er slet ikke saa dum²}

Efrén Rebolledo y Thorborg Blomkvist no pudieron encontrarse antes de 1919. No obstante, el autor bien pudo recrear experiencias reales dentro del marco conceptual de la historia (1916-1919): la confirmación de Sigrid en el templo de Vor Fresler (sic), el baile del "Gymnasie Samfund", después de los debates escolares de los sábados, el desfile de las graduadas por la calle Karl Johan.

Los espacios de esparcimiento que aparecen en la novela son abundantes. Muchos de ellos están ligados a la naturaleza y a la práctica de los deportes de nieve: Holmenkollen, las pendientes de Skiveien, Voksmenkollen (sic), Korketrekkeren, los abetos de Skaandalen (sic) Löiper... En ellos se respira un ambiente de juventud y pureza relacionado con la práctica del esquí y con las bajadas en "trineo" (palabra que nunca se usa en el libro, en beneficio de kjelke, con todas sus resonancias localmente exóticas).

En este marco cartográfico tiene una gran importancia el traumático paso de la nieve al mar. La familia de Sigrida se ha arruinado debido a la Gran Guerra, como otros inversores de la Norske Australie Linie, y debe mudarse a una zona más modesta, de los cerros nevados de Holmenkollen a las humildes costas de Snaören. En la narración los tiempos se solapan, de modo que la relación de Rebolledo con la que sería su mujer tiene lugar en un tiempo que no existe en la "novella" (1919-1921), puesto que el cambio de ubicación hace que Edmundo le pierda el rastro a la joven de quien se había enamorado en las estaciones de Oslo.

Durante ese tiempo, Sigrida está en un internado en Suiza. En el viaje de ida con su madre se detienen en Biarritz, donde siente la vergüenza de bañarse junto a italianos y españoles que se le antojan monos por el estúpido vello que sombrea sus cuerpos cetrinos (Rebolledo 1922 40). Es muy posible que Efrén Rebolledo haya

\footnotetext{
2“Tú no eres nada tonto”, nos aclara el autor en nota a pie de página.
} 


\section{Nordic Journal of Modern Language Methodology}

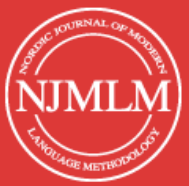

2019, 7 (2), 154-173 Peer reviewed Temanummer: Spansk i Norge og det norske i den spansktalende verden.

querido trazar una evolución -real o metafórica- de la mujer redentora. Snaören aparta a Sigrida de la vida social de Oslo. La acerca a la naturaleza, a la costa, a la Ofelia de Shakespeare, a las heroínas clásicas. En este nuevo espacio practica la natación, como las ondinas, no el civilizado esquí. Sigrida deja de usar el tren para ir a la ciudad, y se ejercita en el balandro y en el bote para recalar en los muelles de Piperviken, en el centro de Cristiania, desde donde enfila la calle de Karl Johan, arteria principal de la ciudad. Modernidad y tradición se interpelan con este cambio. Esto le permite al autor dar otra perspectiva citadina, una visión desde el mar, desde fuera de la actividad moderna. Rebolledo convierte así una cartografía en un estudio verdadero de la psicología de un alma.

Cuando Edmundo y la chiquilla se reencuentren en el Grand Hotel de Cristiania, ya no es un capullo, sino una flor de belleza. (Rebolledo, 1922 46) Es entonces cuando los planos de la historia convergen y se desarrollan coherentemente. La segunda parte de la saga despliega ya el flirteo en su máxima expresión. Sigrida y Edmundo salen juntos por la Cristiania "Art Nouveau". El novelista recurre a lo mejor de su prosa parnasiana para desplegar la verdad y la belleza de una ciudad contemplada como un mapa espiritual. El Parque de la Reina (Rebolledo, 1922 83-84):

Bajo la copa del fresno Igdrasil, y a la orilla de la fuente Urdaria en cuyas linfas claras como espejos pasean los cisnes su soberbiosa blancura, se encuentran las tres Normas, hijas de la llusión, que registran los destinos de los dioses y de los hombres, y que a la sazón posan sus ojos en Sigrida.

La mayor, Urda, tiene un libro en las rodillas y con una pluma de cisne está escribiendo en las páginas virginales; la de en medio, Verdandi, está de pie, y muestra las manos llenas de manojos de flores, Skulda, cubierta con un velo torna la espalda a Urda y atisba con sus ojos penetrantes el horizonte.

Los capítulos VII y VIII están dedicados a la vida cultural de Cristiania a principios de los años 20, al ambiente de los hoteles de una ciudad en la que modernidad y tradición se dan la mano (es decir, una ciudad en la que la modernidad es tradición): recepciones en casa del abogado P. Rogeberg, conciertos en la Logia y en el Aula de la Universidad, que decoró Munch entre 1911 y 1916, veladas en el Teatro Nacional, donde asisten a una representación de El pato salvaje de lbsen, bailes de 


\section{Nordic Journal of Modern Language Methodology}

beneficencia, encuentros en Legaciones, el Salón Rococó del Grand Hotel, al que concurren Haakon VII y la Reina Maud, el Salón de los Espejos, con sus tés y sus cenas, o la orquesta de jazz del Salón de las Palmas, murado de jaspe y enteselado de mármol (Rebolledo, 1922 62).

El Grand Hotel es el lugar del conocimiento, de los bailes en la penumbra y las confidencias en voz baja, el lugar en que ambos enamorados comparten sus vivencias y experiencias, el lugar en que Sigrida introduce a Edmundo en los grandes nombres de la cultura noruega, ejerciendo el papel de mediadora que interpreta los signos jeroglíficos de un modo de vida que el trasunto del novelista está deseando entender: el violinista Ole Bull (1810-1880), amigo del rey de Suecia, Edvard Grieg (1843-1907), tan grande de genio como escaso de estatura, el personaje teatral Juan Gabriel Borkman, que durante el invierno sólo tuvo como asilo un sobretodo.

$\mathrm{Si}$ el Grand Hotel -como digo- es el lugar del conocimiento, el Hotel Bristol es el lugar de la revelación.

\section{La revelación del Hotel Bristol}

El Hotel Bristol abrió sus puertas en 1920, gracias a la iniciativa del empresario Olav Thon. Se encontraba -y se encuentra- situado en la Kristian IVs gate 7, muy cerca de la Ópera Cómica. Hoy en día está remodelado, no corresponde al hotel que se describe en la novela, pero mantiene muchas de las características que podemos reconocer en la misma.

En el capítulo IX Edmundo y Sigrida se refugian en el Hotel Bristol después de salir de la Ópera Cómica. Nieva. Van a pie. Cenan entre sus fastos alhambrescos (Rebolledo, 1922 64). Cigarrillos, lujo, banjos. El ambiente es decadente, pero a la vez jazzístico La irrupción del jazz en Europa es uno de los síntomas más evidentes del fin de la Belle Époque y el advenimiento de la modernidad, es decir, de la vanguardia que se abre paso a cañonazos desde las trincheras de la Europa de la Gran Guerra. Sigrida y Edmundo no se sienten a gusto. Estamos en el invierno de 1921. Es entonces cuando experimentan la sensación de que su arte de vivir ha caducado (Quintana Pareja, 2017), de una forma que Manuel Machado supo compendiar con 


\section{Nordic Journal of Modern Language Methodology}

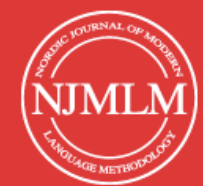

2019, 7 (2), 154-173 Peer reviewed Temanummer: Spansk i Norge og det norske i den spansktalende verden.

una clarividencia absoluta en el prólogo-epílogo de El mal poema (1909): "El médico me manda no escribir más, renuncio a ser un d'Annunzio”. Escribe Rebolledo (1922 64-65):

Después de salir de la Ópera Cómica, una noche va con Edmundo a cenar al Bristol, donde causa furor una orquesta de negros, crismada con el nombre de los "Cinco Diablos del Jazz".

Nieva. $[\ldots]$

La orquesta puebla el salón con los sonidos saltarines de los banjos y el estrépito multífono de la batería. Es una fiesta de algazara y de sol en la noche circundada de nieve y silencio. Evoca susurros de selva y garrulería de aves, esperezamientos de leopardos y ondulaciones de serpientes.

Sigrida y Edmundo bailan también; pero no se sienten a su placer en aquella atmósfera agobiada de humo y resonante de voces, en medio de aquel tropel de parejas cuyos sentidos están intoxicados por los diabólicos acordes de la orquesta, sobre la que se elevan el canto ardiente de los negros, que ríen satánicamente, mostrando sus dentaduras blancas".

No resulta extraño que después de 1922, el escritor mexicano Efrén Rebolledo apenas publique. Su caso es el de tantos otros modernistas que no entendieron, que no aceptaron, ese mundo "moderno" y vanguardista, trepidante como una ametralladora, posterior a la Gran Guerra.

Al salir a la calle, al escapar del tiempo nuevo, su vita nuova se abre paso como una revelación (Rebolledo, 1922 65-66):

A la una termina el baile, y en saliendo ambos sienten ensancharse su pecho con una sensación de alivio, al recibir en las sienes el hálito fresco de la calle.

A partir de este momento la novela toma un giro. Los protagonistas se refugian en el ámbito privado, y evitan los espacios sociales. Sigrida acude cada tarde al apartamento de Edmundo, que vive en Odensgate (sic), junto a la Biblioteca. Es el momento de mayor inocencia de ella y de mayor perversidad de él. El apartamento es un refugio decadente frente a la Modernidad, vislumbrada en el Hotel Bristol: floreros 


\section{Nordic Journal of Modern Language Methodology}

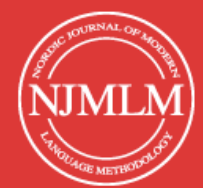

2019, 7 (2), 154-173 Peer reviewed Temanummer: Spansk i Norge og det norske i den spansktalende verden.

de porcelana de Copenhague, cerezas, fruteras y bomboneras de plata, tántalos de cristal.

En este ambiente, Edmundo se regocija en la recreación de su propio amor, no puede dejar de erotizar a Sigrida, de una forma buñuelesca (recordemos Viridiana, 1961), muy cinematográfica (Asta Nielsen, las mujeres fatales del cine italiano, Francesca Bertini, tantas otras). Rebolledo es cinematográfico en este sentido. Hay una fragmentación fetichista (los ojos que se fijan en las medias, en los zapatos, en las manos, etc.). Esta fragmentación sólo puede proceder del montaje fílmico, es decir, de una "reificación" entendida a lo Walter Benjamin (Benjamin, 2012). Hay una celebración de la carne, pero ya es diferente del poemario Caro Victrix, porque es una reificación real. En un cierto momento, Edmundo le pide a Sigrida que se quite el sombrero. Fetichismo. Su pelo rubio. Le toca el pelo (blondas y sedeñas madejas (Rebolledo, 1922 68). Nada más decadente que el pelo en la mujer. Sin embargo, estamos ante un exorcismo que conlleva una revelación, que se expresa en noruego, lengua críptica. Sigrida accede a ser objeto de culto, con unas palabras comunes, pero fuera de contexto (Rebolledo, 1922 84): Vaer saa god!3

Ambos van creando un "léxico familiar", que se expresa en inglés, lenguaje del amor en un mundo que ya no es el suyo. El personaje/escritor explica de este modo lo que las lenguas significan en un entorno cosmopolita (Rebolledo, 1922 54):

No tengo la culpa de no hablar noruego, arguye hablando consigo mismo. Todo el mundo sabe aquí el inglés, el francés o el alemán. Cuanto más que los extranjeros apenas si tienen la oportunidad de tratar a los noruegos que viven su propia vida, sin aceptar el yugo de las servidumbres sociales. Y luego, cuando parta, ¿de qué me sirve el noruego? Sin embargo, el hablar la lengua de un país ayuda a conocer mejor sus costumbres, su literatura, sus instituciones. Sobre todo, si hablara noruego estaría hablando con Sigrida.

Efrén Rebolledo cada vez se parece más a sí mismo, la máscara converge con el himno a la nueva realidad revelada. Declara asombrado su certidumbre: La amada que he buscado en vano y no he encontrado en México, ni en Guatemala, ni en Tokio, ni en

\footnotetext{
3“Frase elíptica que aquí significa pase usted”, nos aclara el autor en nota a pie de página.
} 


\section{Nordic Journal of Modern Language Methodology}

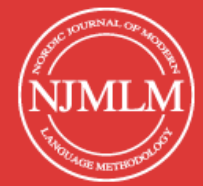

2019, 7 (2), 154-173 Peer reviewed Temanummer: Spansk i Norge og det norske i den spansktalende verden.

Nueva York, ni en Estocolmo, ni en Copenhague ni en París (Rebolledo 1922 51).

Ella es práctica, él poético. Ella se fija en que no tiene cortinas oscuras en "la alcoba" (en la novela decadente hay "alcobas" en vez de "dormitorios"). Sobre la oscuridad, que él interpreta simbólicamente, ella dice: Hay gente que pierde el juicio en el norte de Noruega (Rebolledo, 1922 85). Cuando toman vino de Oporto, a las copas las llaman "cálices". La revelación del Hotel Bristol ha hecho que la realidad se reifique en un amor que no pertenece al tiempo, que refuta el tiempo, que salva.

\section{Parnasianismo culturalista}

Efrén Rebolledo representa en las letras hispanas un eje parnasiano, que consiste en un pulimento de la forma muy preciso, que en esta novela se decanta desde su primer párrafo, que contiene una referencia a la "Adoratio" (1909) de Sinding (Rebolledo 1922 7-8):

Existe en la Gliptoteca de Copenhague un grupo de mármol "Adoratio", del admirable escultor noruego Stephan Sinding, que muestra una virgen castamente desnuda sentada en un plinto cuadrangular, de modesto semblante de madona y con los finos brazos cayendo a plomo a los lados del seno en sazón, a cuyas plantas yace postrado un mancebo de igual manera desnudo, que en trance de idolátrico acatamiento, le toca las manos reverentes y le besa con labios devotos las mellizas piernas de inviolada blancura, sin que obscurezca la pureza de su homenaje la presencia del áspero deseo.

En el plinto de la escultura de Sinding se puede leer en francés el título de una película de Jean-Luc Godard: Un homme et une femme (1961). Pero esto nos llevaría muy lejos. Por lo demás, no es posible hacer referencia a las decenas de citas culturales en relación con la cultura noruega que aparecen en la "novella" de Rebolledo. Me centraré, por tanto, brevemente, en las dos que me resultan más relevantes. Sigrida y Edmundo se pasan la vida leyendo. Sigrida lee a Knut Hamsun (especialmente la novela Victoria, 1898), toca piezas de Grieg al piano, o mira caer la nieve como buena doncella hiperbórea (Rebolledo, 1922 23). Estamos, por tanto, en la dialéctica decadentista -tan bien estudiada por Lily Litvak (1979)- de la mujer como rosa mística.

Todo el capítulo XIII es un homenaje a Henrik Ibsen y Bjørnstjerne Bjørnson, las dos sombras tutelares de la literatura noruega en el panorama internacional de la época. Edmundo 


\section{Nordic Journal of Modern Language Methodology}

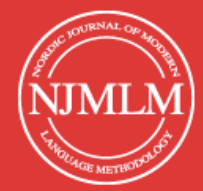

2019, 7 (2), 154-173 Peer reviewed Temanummer: Spansk i Norge og det norske i den spansktalende verden.

le pide a Sigrida visitar el cementerio de Vor Freiser (sic) (Vår Frelsers gravlund), porque quiere que le traduzca los versos de lbsen entallados en la lápida de su mujer. (Rebolledo, 1922 95). Rebolledo convierte este capítulo en una excelsa interpretación filológica para mayor gloria del "cisne de Skien“ (Rebolledo, 1922 96-97):

Juntos reposan en el cementerio de Vor Freiser (sic), el uno en su túmulo de granito, y el otro en su mausoleo de lóbrega labradorita. Juntos resplandecen en el monumento de erudita apreciación en que los ensalza el sagaz y sabio crítico George Brandés. Juntos se yerguen ante la fachada del Teatro Nacional vaciados en bronce por el genio de Sinding.

Fueron noruegos y contemporáneos. Su afinidad no pasa de allí. Björnson es noruego hasta la médula e Ibsen es humano. Björnson es un corazón palpitante e Ibsen un cerebro creador. Björnson es venerado en el sagrario escandinavo e Ibsen descansa en el panteón donde culminan Esquilo y Shakespeare. Björnson es el Dios Thor garrudo y batallador, e lbsen es Odín hosco y taciturno que mora en su cúspide inaccesible, y que todo lo abarca, porque ha bebido el agua de la fuente de la sabiduría.

De fúnebre labradorita es el sepulcro de lbsen.

En la luciente negrura del obelisco resalta el entalle de un martillo en reminiscencia de su poema "El minero". "Voy a abrirme paso en la piedra hasta oír el sonido del metal; hazme camino, pesado martillo, hasta la morada del corazón". Ni nombre ni fecha. No los necesita. No los han menester los venerables abetos ni las montañas augustas. No tiene principio ni fin la eternidad. sobre la lápida luctuosa yace una corona de hierro, propia para ceñir las sienes del escalda formidable que fue pino taciturno y oso solitario, mar acerbo y cumbre orgullosa.

Sigrida actúa de mediadora, ya que, al lado de lbsen, descansa su mujer bajo una lápida negra (Rebolledo, 1922 98):

Nunca he podido entender estos versos, le dice Edmundo, y Sigrida le traduce amorosamente el sencillo epitafio, que ilumina la oscura labradorita como un rayo de luna:

Era un escollo su amargura que embarazaba mi destino $y$ de tropiezos en ventura dejaba libre mi camino.

Su objeto fue siempre inflamada 


\section{Nordic Journal of Modern Language Methodology}

Temanummer: Spansk i Norge og det norske i den spansktalende verden.

tener mi ánima de ardor

sin revelar a la mirada

que ella era el soplo bienhechor.

\section{Nordismo, feminismo y otras costumbres modernas}

La nordomanía, el nordismo hispánico, entiende que Escandinavia es un territorio periférico, como España, es decir, fuera del centro intelectual de la época, París, la ciudad-luz. En relación con dicho centro se dibuja un eje norte/sur, que une "el trópico y el polo", para usar las palabras exactas de Rebolledo. La pregunta que el autor se plantea es si es posible conciliar lo hispano y lo nórdico, es decir, el Finisterre y la Última Thule. Efrén Rebolledo, como mexicano, no duda en simbolizar en la corriente del Golfo la posible confluencia de ambas periferias (Rebolledo, 1922 61-62):

El trópico y el polo, distantes como están, se comunican por medio de la corriente del Golfo Mexicano; a pesar de ser tan disímbolos, el día y la noche se besan al despuntar el alba en un lecho de marfil, y el cielo y la tierra, entre los que media un infinito, se desposan en un tálamo de turquesas.

En todo caso, las diferencias se manifiestan claramente: una sociedad luterana frente a una sociedad católica, una sociedad feminista frente a otra en la que la mujer disfruta de menos libertades.

En la "novella" se alude al triunfo de las ideas de la escritora Camilla Collett (Kristiansand, 1813-Cristiania, 1895), se hace referencia a la realidad de los personajes femeninos de lbsen (Hedda Gabler, Nora...). La situación de la mujer en Noruega provoca un choque cultural en el erotómano Rebolledo, relacionado con el conocimiento de la que sería su mujer (Sigrida/Sigrid). En la saga, el español Edmundo monologa desconcertado (Rebolledo, 1922 60-61):

[...] ... cada noruega es una Nora o una Hedda Gabler [...] Esa libertad de la que se ufana la mujer noruega, esa independencia de las señoritas casi igual a la de los hombres, que les permite ir solas con sus amigos a la montaña o al fjord, al teatro o al restaurant, ¿no las expone a peligros? La perla, en el alhajero. El tesoro, escondido. La oveja en el aprisco o a los ojos del zagal. [...] ¿... será cuerdo que le dé el título de esposa a una mujer que no será solamente sumisión y dulzura, sino que, pues es noruega, tendrá un alma presta a la 


\section{Nordic Journal of Modern Language Methodology}

2019, 7 (2), 154-173 Peer reviewed Temanummer: Spansk i Norge og det norske i den spansktalende verden.

libertad y a la rebelión? [...]

Sin embargo, Rebolledo no suprime el razonamiento de Sigrida; al contrario, también ella medita si es prudente aceptar el amor de un español, un ser que tiene un alma diferente de la mía, un hombre de pasiones de moro, tal vez (Rebolledo, 1922 59).

\section{Antonio de Zayas en Estocolmo y el regeneracionismo que viene del Norte}

En cierto modo, Rebolledo depura su erotomanía en Noruega, la hace natural, no artificiosa ni decadente. La Saga de Sigrida la Blonda (1922) es un elogio de Noruega como espacio de pureza y como modelo de regeneración de España y de la América Española después del Desastre de 1898 y de la Gran Guerra.

Antonio de Zayas-Fernández de Córdoba y Beaumont, duque de Amalfi (Madrid, 1871-Málaga, 1945), diplomático y poeta modernista casticista, pasó varios años en Suecia en dos estancias diplomáticas. La primera fue de diciembre de 1902 a julio de 1904. En la revista modernista Helios se publican colaboraciones suyas fechadas en Estocolmo, como, por ejemplo, un texto sobre Góngora y Antonio Machado (Helios, 1, 159-161, f. 23 abril 1903).

Esta primera etapa olmense termina antes de que la Academia Sueca le conceda el Premio Nobel de Literatura a Echegaray (1904), lo que provoca una carta de protesta contra el dramaturgo (marzo de 1905), que el propio Zayas firma.

La segunda estancia diplomática en Escandinavia tuvo lugar durante la Gran Guerra (1914-1918). Se trata de un período menos conocido que el primero. De hecho, en las bibliotecas suecas -en especial en la Kungliga biblioteket de Estocolmo-, se encuentran con relativa facilidad libros suyos del período 1902-1910: Joyeles bizantinos (1902), Retratos antiguos (1902), Paisajes (1903), Noches blancas (1905), Leyenda (1906), Ensayos de crítica histórica y literaria (1907), Reliquias (1910). En todo caso, hay un escrito de Zayas que tiene especial relevancia para entender la visión periférica de Suecia, en relación con la cultura latina. Se trata del escrito "Psicología y costumbres del pueblo escandinavo", incluído en el libro Ensayos de crítica histórica y literaria (1907 179-235). 


\section{Nordic Journal of Modern Language Methodology}

En un contexto de propuestas regeneracionistas que surge a partir del Desastre del 98, Zayas tiene la originalidad de proponer un modelo casticista basado en la periferia escandinava, que puede ser resumido en los siguientes puntos:

- Zayas considera que las características del pueblo sueco son independientes de su religión. Lamenta que Gustavo Vasa los hiciera luteranos, pero piensa que, si fueran católicos, actuarían igual. Por este motivo, las virtudes escandinavas pueden alcanzar un mayor grado de desarrollo en un pueblo católico como el español.

- Le llama la atención el silencio y el pudor de los suecos, virtudes positivas que tienen que ver con el clima (el frío obliga a la disciplina para sobrevivir, mientras que el clima cálido favorece la pereza, ya que la supervivencia se da sin esfuerzo), y que fomentan la perseverancia de la voluntad, más amiga de laborar sordamente que de levantar estrépito con la predicación de redenciones utópicas. Los suecos defienden sus tradiciones, al mismo tiempo que están abiertos a la innovación moderna.

- Alaba el sistema educativo sueco, basado en una potente instrucción primaria, una doctrina moral sólida, y una educación superior escasa, pero focalizada en líneas de investigación eficaces, debido a la tenacidad en el esfuerzo.

- La tesis central del ensayo se basa en la búsqueda de un modelo alternativo al francés, con vistas al mejoramiento y regeneración de nuestra patria. Escandinavia puede representar ese modelo nuevo, menos decadente que 10 que nos viene de Francia, más centrado en el hacer que en el aparentar, más orientado al bienestar material por que (sic) nosotros tan viva e irreflexivamente suspiramos.

- Zayas resalta un gran contraste entre Suecia y España, que tiene relación con la falta de imaginación. La monotonía del paisaje sueco se corresponde con la monotonía de su alma, pero refuerza sus hábitos de trabajo, su constancia, que es lo que le falta a España, donde la mayor imaginación se pierde por falta de perseverancia.

- Los grandes defectos de Suecia son: el egoísmo y la hipocresía (propio de los pueblos luteranos), su tendencia (lógica, para defenderse del frío) al 


\section{Nordic Journal of Modern Language Methodology}

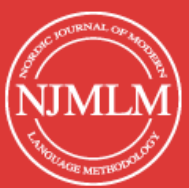

2019, 7 (2), 154-173 Peer reviewed

Temanummer: Spansk i Norge og det norske i den spansktalende verden.

alcoholismo, y su relajación moral en las relaciones entre hombres y mujeres.

Sus grandes virtudes: la tenacidad y la honestidad.

En definitiva, Zayas se sitúa con este ensayo en la línea del regeneracionismo maurista, católico y conservador, alejado de Francia. El mejoramiento de España debe venir, en su opinión, de un casticismo basado en modelos más eficientes y limpios, que proyecta en Escandinavia, con la salvedad de sus costumbres sexuales.

Podemos considerar que la estancia de Efrén Rebolledo en Noruega tiene unos efectos similares en su posición frente al modernismo decadente y parnasiano, que él mismo, como Zayas, habían representado. En este sentido, lo nórdico tiene un efecto regenerador que se basa en una pureza radicada en la periferia.

\section{Conclusión}

La obra a la que nos hemos acercado en este estudio sigue olvidada desde su publicación. Suele recibir, incluso, una atención más bien peyorativa (Sheridan, 1977 45):

Saga de Sigrida la Blonda (1921) (sic) es una pésima novela que, sin embargo, es genial en cuanto que es un catálogo de procederes modernistas.

Sin embargo, hemos querido resaltar las cualidades de la obra, y su incardinación con el regeneracionismo hispánico posterior al Desastre del 98. La "periferia" (Norte-Sur) es lo que une lo español y lo escandinavo a principios del siglo $X X$, en relación de contraste con un centro que estaría situado en París (Stadius, 2005). Esta operación intelectual se sitúa, dentro de un debate en torno a modelos sociales y culturales alternativos al francés, en países "periféricos" como Bélgica (Quintana Pareja, [en prensa]) o Noruega. Cada uno a su manera, tanto Rebolledo como Zayas se constituyen en eslabones que cierran una especie de cadena sanitaria por el Norte, poniendo a Escandinavia como ejemplo para la regeneración de España a principios del siglo XX. Así se deduce de estas palabras de Zayas (1907):

El espíritu francés es antagónico del espíritu escandinavo; aquél es de percepción rápida, éste de asimilación tardía; el uno es frívolo, ágil, deslumbrante; el otro grave, rígido, sombrío; el francés ama las síntesis, es apto para las condensaciones superficiales; el sueco es devoto del análisis, idóneo 


\section{Nordic Journal of Modern Language Methodology}

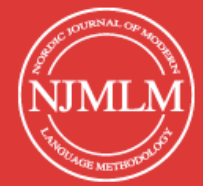

2019, 7 (2), 154-173 Peer reviewed Temanummer: Spansk i Norge og det norske i den spansktalende verden.

para abismarse en alambicar los detalles."

Saga de Sigrida la Blonda (1922) es una obra extraordinaria, que merece un estudio más profundo, así como una reedición crítica, que la sitúe como una pieza mayor de su autor y de la literatura de su época.

\section{Bibliografía}

Bolaño, Roberto. Los detectives salvajes. Barcelona: Anagrama, 1998. Impreso.

\section{Barrera Barrios, Susana Elena. La mujer fatal en "Salamandra" de Efrén}

Rebolledo. Estudio del personaje femenino modernista. Universidad de Sonora, 2010.

https://www.academia.edu/6085141/Licenciatura_La_mujer_fatal_en_Salamandra_ de_Efr\%C3\%A9n_Rebolledo. Estudio_del_personaje_femenino_modernista

Benjamin, Walter. La obra de arte en la época de su reproductibilidad técnica. México: Porrúa, 2012. Impreso.

Bogarín Quintana, Mario Javier (2010). Memorial japonés de Efrén Rebolledo. Universidad de Baja California, 2010. Obtenido el 15 de noviembre de 2018. Sitio web: https://www.researchgate.net/publication/272493486_Memorial_japones_de_Efren_ Rebolledo

Escamilla Frías, Luis E. "Efrén Rebolledo y Caro victrix. El diablo y su creatura." Opción 144 (2007): 22-34. Web. 15 Nov. 2018. http://tiraderofrias.blogspot.se/2007/03/blogpost_22.html

Estrada Rubio, Libertad. "Introducción" El enemigo. México, UNAM, col. "Relato Licenciado Vidriera”, 2015: VII-XXVI.

Litvak, Lily. Erotismo fin de siglo. Barcelona: Bosch Editor, 1979. Impreso.

Mata, Óscar: La novela corta mexicana en el siglo XIX. México: UNAM, 2003. Impreso.

López Pellicer, Juan. "Poeta en Christiania: Atisbo histórico-literario al modernismo de Efrén Rebolledo" Revue Romane 49.1 (2014): 147-157. Impreso.

Quintana Pareja, Emilio. "Un cerebro que hace jazz sin cansancio. El "jazz" como meridiano de la modernidad tras la Gran Guerra" El Rapto de Europa 37.1 (2017): 39-46. Impreso.

Quintana Pareja, Emilio. "Don Quixote in the Trenches. The Birth of the Avant-Garde Poetry in Spanish language between Civilization and Barbarism" [en prensa] 


\section{Nordic Journal of Modern Language Methodology}

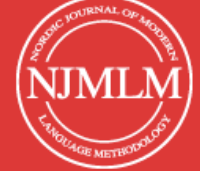

2019, 7 (2), 154-173 Peer reviewed Temanummer: Spansk i Norge og det norske i den spansktalende verden.

Rebolledo, Efrén. Saga de Sigrida la blonda. Kristiania: Det Mallingske Bogtrykkeri, 1922. Impreso.

Rebolledo, Efrén. Obras reunidas de Efrén Rebolledo. Ed. B. Rocha. México: Editorial Océano de México, 2004. Impreso.

Rebolledo, Efrén. Salamandra (1922). México: UNAM, 2009. Edición y notas de Milenka Flores García. Presentación de Christian Sperling. Web. 15 Nov. 2018. http://www.lanovelacorta.com/1872-1922/pdf/salamandra.pdf

Sheridan, Guillermo. "Centenario de Efrén Rebolledo. Saga de Sigrida la Blonda: el papel de la convención." Revista de la Universidad de México 11 Julio (1977): 44-45. Web. 15 Nov.

http://www.revistadelauniversidad.unam.mx/ojs_rum/index.php/rum/article/view/10462

Stadius, Peter. Resan till norr. Spanska Nordenbilder kring sekelkiftet 1900. Helsingfors: Finska Vetenskaps-Societeten, 2005.

Valencia, Alfonso (2014). "Cinco párrafos sobre Santiago Procopio, alias Efrén." Milenio 4.07.2014. Obtenido el 10 de febrero de 2018. Sitio web: http://www.milenio.com/firmas/alfonso_valencia/parrafos-Santiago-Procopio-aliasEfren_18_329547111.html

Zayas, Antonio de. "Psicología y costumbres del pueblo escandinavo." Ensayos de crítica histórica y literaria. Madrid: Imprenta A. Marzo, 1907: 179-235. Web. 15 Jun. 2018. https://es.wikisource.org/wiki/Ensayos_de_cr\%C3\%ADtica_hist\%C3\%B3rica_y_liter a_ria/Psicolog\%C3\%ADa_y_costumbres_del_pueblo_escandinavo

Økland, Ingunn (2015). "Sørgedikt uten skjønnmaling." Aftenposten 1.05.2015. Web. 15 Nov. 2018. https://www.aftenposten.no/kultur/i/geaA/Sorgedikt-uten-skjonnmaling 